\title{
Pandemia SARS-CoV-2: A Perspetiva do Laboratório de Patologia Clínica do Hospital CUF Infante Santo \\ E tudo o SARS-CoV-2 mudou...
}

\section{Hospital CUF Infante Santo Clinical Pathology Laboratory Approach on Pandemic SARS-CoV-2}

How everything changed with SARS-COV-2 ...

Margarida Albuquerque ${ }^{1,3}$, Maria José Sousa ${ }^{3}$, Maria Favila Menezes ${ }^{2,3}$, Ana Guia Pereira ${ }^{3}$, Rita Ribeiro ${ }^{3}$, José Germano de Sousa ${ }^{3}$, Germano de Sousa ${ }^{3}$

Autor Correspondente/Corresponding Author: Margarida Albuquerque [malbuquerque@germanodesousa.com] Rua Cupertino de Miranda Nº 8, 1600-513 Lisboa, Portugal ORCID iD: 0000-0003-1165-4790

PALAVRAS-CHAVE: COVID-19; Laboratórios Hospitalares; Pandemia; SARS-CoV-2

KEYWORDS: COVID-19; Laboratories, Hospital; Pandemics; SARS-CoV-2

\section{INTRODUÇÃO}

A infeção a SARS-CoV-2, o coronavírus, obrigou à alteração da dinâmica de todos os serviços e unidades hospitalares que prontamente se evidenciaram como estruturas hospitalares diferenciadas e especializadas no diagnóstico e tratamento desta doença que aos poucos fomos conhecendo.

Os primeiros artigos e conhecimento chegava-nos da China, a uma velocidade alucinante, mas cautelosa, e todos os conceitos, estratégias de diagnóstico e de terapêutica eram desmoronadas todas as semanas.

Ao Laboratório de Patologia Clínica desde as primeiras horas, foi colocado o enorme desafio de dar resposta aos colegas que no Atendimento Permanente recebiam os doentes com quadros clínicos que dentro da sua heterogeneidade, se foram tornando cada vez mais suspeitos, com cada vez menos sinais e sintomas.

Não foi apenas o diagnóstico molecular por RT-PCR (reverse transcriptase polimerase chain reaction) que foi transformado numa metodologia "banal" no atendimento permanente, mas todo um conjunto de parâmetros que a pouco e pouco se foram evidenciando como um painel de suspeição da gravidade da infeção a SARS-CoV-2. Novos parâmetros e novas metodologias ficaram disponíveis em Urgência no Laboratório de Patologia clínica do Hospital CUF Infante Santo, p. ex. ferritina 
e interleucinas 1 e 6 (IL-1 e II-6), que suportado por toda uma máquina, que no Centro de Medicina Laboratorial Germano de Sousa, permitia dar resposta 24/7 aos pedidos de diagnóstico molecular.

Todo um laboratório foi restruturado e adaptado, com reforço de recursos humanos, equipas de técnicos, médicos e logística, aquisição de novos equipamentos e execução de novas metodologias, lutando diariamente para que o doente fosse precocemente diagnosticado e tratado, sem nunca sentir o nosso desgaste e pressão.

Passada a chamada primeira vaga, achamos todos que "sobrevivemos" e que renasceremos mais fortes e com mais conhecimento de mais esta provação.

Faremos um resumo de todos os aspetos revelantes relacionados com o diagnóstico e monitorização laboratorial da infeção SARS-CoV-2 implementados em HCIS-CMLGS na resposta à pandemia COVID-19, com especial relevo para a articulação com as várias vertentes clínicas desta unidade hospitalar.

\section{PROCEDIMENTOS TÉCNICOS E DIAGNÓSTICO LABORATORIAL TIPO DE AMOSTRA}

A probabilidade de obtenção de um resultado positivo pode variar com o tipo de amostra biológica, a qualidade da colheita e a dinâmica da carga viral, ou seja, da quantidade de RNA viral presente numa determinada localização anatómica e em cada fase e gravidade da doença.

No âmbito da realização de testes para o diagnóstico da COVID-19, o Centro de Medicina Laboratorial Germano de Sousa (CML-GS), de acordo com as recomendações da Direção Geral da Saúde (DGS) ${ }^{1}$ e do Center for Disease Control and Prevention (CDC), ${ }^{2}$ deu preferência à colheita de amostra na nasofaringe.

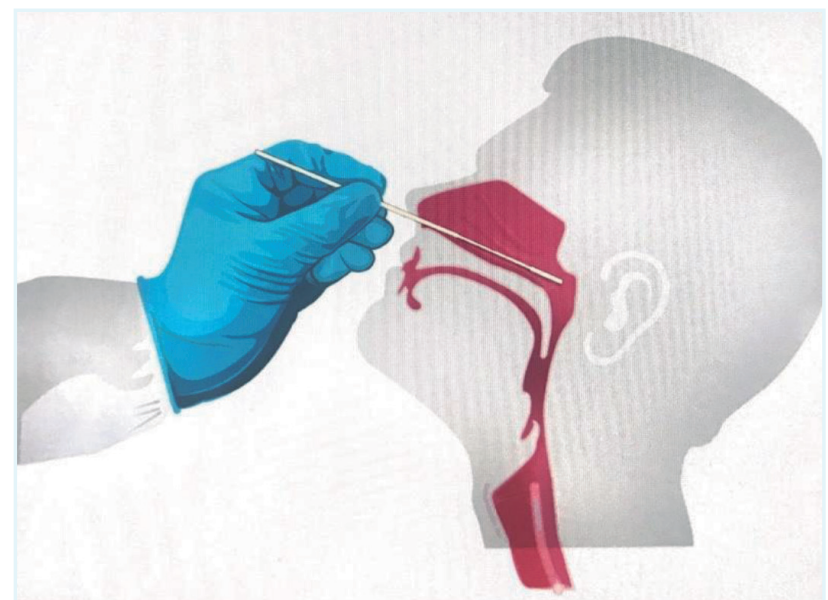

FIGURA 1. Colheita de amostra da nasofaringe.
Em termos de amostra respiratória superior, a amostra da nasofaringe é a mais indicada. 3,4

A recuperação de partículas virais é mais sensível neste tipo de amostra do que utilizando a amostra orofaríngea, ${ }^{3}$ e não se verificou um aumento na sensibilidade analítica do teste quando se associam as duas amostras. Outro ponto particularmente importante do ponto de vista da segurança do profissional de saúde que faz a coIheita, é o risco acrescido para este, com a possibilidade da colheita da amostra orofaríngea ser mais complexa quer em termos de contaminação da amostra (estruturas adjacentes da cavidade oral que se devem evitar durante a colheita), quer com a estimulação do reflexo da tosse com emissão de aerossóis e desta forma colocar em risco o colaborador que realiza a colheita, apesar da utilização devida do equipamento de segurança individual (EPI).

A amostra da orofaringe é usada apenas em alternativa ${ }^{4}$ sobretudo em contexto de patologia do foro de Otorrinolaringologia (ORL), ou se a colheita de amostra nasofaríngea foi traumática (a contaminação com sangue inviabiliza a realização da técnica de PCR).

Apesar de no início da pandemia termos utilizado duas zaragatoas, a limitação nacional de fornecimento de material para as colheitas, obrigou a que se realizasse a colheita utilizando apenas uma zaragatoa para a colheita bilateral da amostra nasofaríngea.

A percentagem de positividade de todas as amostras processadas em CML GS, 5,95\%, representando cerca de $22,85 \%$ dos casos positivos nacionais, tem sido sempre mantido (mesmo quando as colheitas incluíam duas zaragatoas), mantendo a confiança quanto aos resultados obtidos e aos procedimentos de colheita instituídos.

\section{TÉCNICA DE COLHEITA}

A técnica de colheita é determinante para a obtenção de uma amostra adequada. Todos os técnicos receberam formação sobre a técnica de colheita de amostra da nasofaringe $^{2}$ (Fig. 1).

Esta formação foi disponibilizada através de comunicações internas com suporte bibliográfico adequado assim como através de vídeos educativos difundidos pelo núcleo de formação CML-GS de acordo com a técnica de colheita publicada como vídeo de demostração pelo New England Journal Medicine 5 https://www.nejm.org/ doi/full/10.1056/NEJMvcm2010260 e posteriormente adaptado para português pelo Centro Hospitalar de Vila Nova de Gaia-Espinho6 https://youtu.be/PYFSQJz7FoU. 


\section{PREPARAÇÃO E ACONDICIONAMENTO DE AMOSTRAS}

Os procedimentos de preparação da amostra para o transporte, garantindo toda uma cadeia de valor no que diz respeito às normas de redução de risco de contaminação dos recipientes primários e secundários, obrigou à elaboração de novos procedimentos internos, próprios para o acondicionamento e transporte das amostras suspeitas de SARS-CoV-2, de acordo com as normas da DGS, CDC e OMS.1,2,7

Foram realizadas várias sessões de treino e de monitorização dos passos dos novos procedimentos, todos formalizados em instruções técnicas validados pelo departamento de Qualidade e Direção Técnica CML-GS e transversalizados a todos os técnicos através de sessões de formação e de treino prático nas várias unidades Hospitalares.

\section{TRANSPORTE E APOIO LOGÍSTICO}

As amostras são transportadas de acordo com as normas da Direção Geral da Saúde (DGS) e da Organização Mundial da Saúde (OMS)1,7 garantindo a integridade e viabilidade das mesmas.

A implementação de um circuito de apoio logístico com transporte de amostras Urgentes e Emergentes 24/7 para o Centro de Medicina Laboratorial onde o Laboratório de Biologia Molecular estava igualmente a processar amostras ao mesmo ritmo, representou um enorme esforço, com o reforço de equipas técnicas e médicas bem como de equipamentos e novas metodologias.

\section{DIAGNÓSTICO MOLECULAR}

Para poder responder de forma adequada às solicitações dos seus doentes, a secção de patologia molecular do Centro de Medicina Laboratorial Germano de Sousa incrementou a sua capacidade de diagnóstico laboratorial de SARS-CoV-2. Esta necessidade de resposta obrigou à formação imediata de equipas técnicas capazes de responder 24 horas por dia durante 7 dias por semana, à aquisição de novos equipamentos de extração e deteção de ácidos nucleicos e a uma adaptação do espaço laboratorial existente, permitindo uma automação de todo o processo laboratorial com elevada qualidade e eficiência. No início, a capacidade de entrega de reagentes e equipamentos por parte das diversas casas comerciais era diminuta e foi necessário testar e validar praticamente todos os reagentes destinados ao diagnóstico de SARS-CoV-2 existentes no mercado. Atualmente, o Centro de Medicina Laboratorial Germano de Sousa, dispõe de duas salas de preparação de amostras com câmaras de classe II (biossegurança nível 2 - BSL2) com capacida- de para 4 elementos técnicos em simultâneo dedicados ao processo de inativação viral das amostras a analisar, dispõe de 8 extratores automatizados: 2 EasyMAg (Biomerieux) que processam 24 amostras cada, 2 Hamilton/ kPCR (Siemens) que processam 96 amostras cada, 3 Chemagic 360 (Perkin Elmer) que processam 96 amostras cada e um Hamilton Nimbus (Werfen) que processa 72 amostras. Todos estes equipamentos utilizam o método baseado em beads magnéticas para extração de RNA viral a partir de amostras respiratórias colhidas de acordo com as orientações nacionais e internacionais. A amplificação e deteção de regiões específicas de SARS-CoV-2 é realizada com o kit EuroRealTime SARS-Cov-2 (Euroimmun), o método utilizado é o designado pela DGS como método de referência: reação em cadeia da polimerase em tempo real precedida de transcrição reversa (rRT-PCR). As regiões alvo específicas do genoma do vírus SARS-CoV-2 são uma parte da região ORF1ab e uma parte do gene $N$ (nucleoproteína). A amplificação é realizada em cada um dos 4 CFX96 (BioRad) de que dispomos.

A sensibilidade analítica (limite de deteção) do kit utilizado está descrita como sendo de 0,68 cópias/uL (95\% intervalo de confiança: 0,43 a 1,43 cópias/uL), apresenta uma especificidade de $100 \%$ e uma sensibilidade clínica de $98,2 \%$.

O Centro de Medicina Laboratorial participa em dois esquemas de Avaliação Externa da Qualidade, um nacional e outro internacional, para o diagnóstico laboratorial de SARS-CoV-2.

\section{MONITORIZAÇÃO DA RESPOSTA IMUNOLÓGICA}

Os testes serológicos, automatizados e rápidos, detetam a presença de anticorpos IgA, IgM e IgG para o SARS-CoV-2. Sendo testes de deteção da resposta imunológica, não estão recomendados para o diagnóstico de novos casos de COVID-19. No entanto, devidamente validados, estes testes revestem-se de enorme importância e são cruciais para fazer o acompanhamento da resposta do sistema imunológico à infeção por SARS-CoV-2.

A sensibilidade clínica do teste serológico lgM e lgG, quando usado em combinação, é de $98,5 \%$ e a especificidade clínica é de 98,7\%. O teste serológico, quando usado em combinação, tem especial indicação clínica:

1. Avaliação da resposta imunológica após uma infeção aguda documentada pelo teste de RT-PCR;

2. Pessoas assintomáticas que foram ou não contacto de doentes COVID-19 confirmados; 
3. Doentes com doença ligeira (e consequente baixa carga viral) e resultados RT-PCR negativo;

4. Pessoas que foram contactos de doentes COVID-19 confirmados, após período de quarentena de 14 dias.

De acordo com a evidência científica disponível atualmente o anticorpo da classe IgM é detetável, na maioria dos casos entre o sétimo e o décimo dia, embora nos casos mais graves possa ocorrer entre o terceiro e o quinto dia após o início dos sintomas. $\bigcirc$ anticorpo da classe IgG é detetável entre os $10^{\circ}$ e o $20^{\circ}$ depois do início dos sintomas. ${ }^{8-10}$

A seroconversão da IgM e IgG parece ocorrer entre a terceira e quarta semana depois do início da infeção. Depois disso, os títulos de IgM diminuem, comparativamente com a IgG que pode persistir para além das sete semanas após a infeção por SARS-CoV-2.11,12

Durante a fase de convalescença, os títulos de IgG podem aumentar cerca de 4 vezes em relação ao valor da fase aguda. Os níveis de IgG atingem a fase de "plateau" cerca de 1 semana depois da seroconversão-10 (Fig. 2).

A evidência científica atual ainda não nos permite afirmar que um título elevado de anticorpos IgG anti SARS-CoV-2 é garante de imunidade efetiva ou duradoura, quando detetados em indivíduos sintomáticos ou assintomáticos.

O teste serológico efetuado pelo Centro de Medicina Laboratorial Germano de Sousa é um imunoensaio por quimioluminescência in vitro (CE-IVD), que permite a determinação quantitativa de anticorpos das classes IgM e IgG para o novo coronavírus (SARS-CoV-2), em plasma ou soro humano.

O Centro de Medicina Laboratorial participa em dois esquemas de Avaliação Externa da Qualidade, um nacional e outro internacional, para a avaliação da resposta imunológica ao SARS-CoV-2.

Com o início dos inquéritos de seroprevalência regional e nacional com os quais o CML GS colabora desde o seu início, foram adquiridas novas plataformas automatizadas com equipamentos de elevado débito para a deteção quantitativa de anticorpos totais (lgM+lgG) por quimioluminescência.

Dada a complexidade da interpretação da cinética da resposta imunológica foram construídas mensagens explicativas dos resultados da serologia, permitido ao clínico uma melhor compreensão e integração dos resultados obtidos.

\section{ARTICULAÇÃO COM OS VÁRIOS SERVIÇOS HOSPITAL CUF INFANTE SANTO}

\section{ATENDIMENTO PERMANENTE}

Desde o início da pandemia COVID-19 e numa altura em que o Hospital CUF Infante Santo foi Hospital de referência na região de Lisboa para receber em internamento doentes infetados de todas as unidades CUF, bem como Hospital de apoio ao SNS, que a articulação com o Atendimento Permanente foi determinante para que esta resposta fosse eficiente.

Para responder à necessidade de identificar precocemente doentes com patologia do foro respiratório infetados com SARS-CoV-2, foram definidos 2 tempos de resposta para doente Urgentes ou Emergentes.

Foi criado um grupo de comunicação 24/7 entre todos os clínicos com função de coordenação das equipas médicas do atendimento permanente, e todos os elementos da escala de prevenção de patologia clínica. Deste

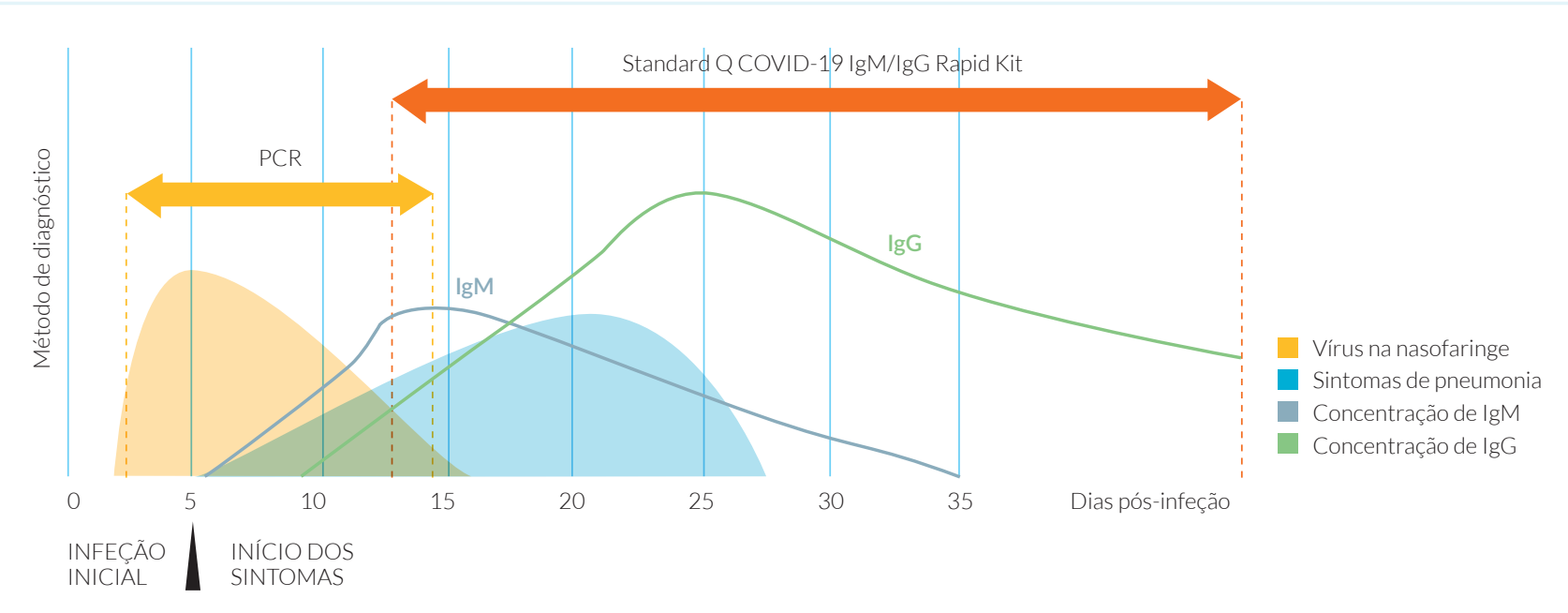

FIGURA 2. Cinética da serologia SARS-CoV-2. 
modo, todos os casos estratificados por gravidade clínica foram assinalados e devidamente rastreados.

Ao médico patologista clínico cabia a responsabilidade de articular com a equipa de técnicos HCIS e com a equipa de biologia molecular de CML-GS, e fazer a identificação destes doentes, bem como a monitorização da saída do respetivo resultado.

A comunicação do resultado foi feita com reporte telefónico 24/7 diretamente para o contacto do médico de coordenação do atendimento permanente, acompanhado da publicação da evidência do resultado e assinatura no sistema informático. A disponibilidade imediata do resultado no processo clínico de todos os casos assinalados ou sempre que de um caso positivo se tratasse, permitiu fazer a gestão clínica eficiente destes casos, com decisão de internamento ou de transferência para unidades hospitalares não COVID.

Ao atendimento permanente cabia a responsabilidade de comunicar e contactar o doente que tivesse tido alta por não ter critérios para internamento.

\section{INTERNAMENTO COVID}

A restruturação do internamento de acordo com as normas de segregação de doentes infetados, obrigou à implementação de novas regras para os técnicos do laboratório que se deslocam aos pisos de internamento para a realização das colheitas programadas.

A articulação com as sessões de formação desenvolvidas pela PPCIRA e relação com os elos de ligação do internamento permitiu a integração das equipas do laboratório nos procedimentos de utilização de EPI validados em
HCIS, no cumprimento dos circuitos de movimentação de pessoas e amostras com total segurança e integridade dos procedimentos de colheita, acondicionamento e transporte de amostras.

\section{UNIDADE DE HEMODIÁLISE}

O Laboratório realizou por 2 ocasiões rastreio em doentes de hemodiálise na unidade do Hospital CUF Infante Santo. Neste momento em que esta unidade se posicionou como unidade diferenciada para receber doentes infetados de outras unidades de hemodiálise, a colaboração prendeu-se com a monitorização de doentes infetados até à fase de obtenção de um resultado negativo do teste de RT-PCR para SARS-CoV-2.

\section{AMBULATÓRIO}

Após a reabertura da atividade programada, foram definidos critérios de rastreio a todos os doentes com uma antecedência de 48 horas, que incluía a realização dos testes à COVID-19, integrando as rotinas pré-exames complementares de diagnóstico invasivos com sedação bem como nas cirurgias eletivas.

Para dar reposta às necessidades HCIS e para que o teste fosse realizado preferencialmente na unidade CUF a que se destina, foram disponibilizados 2 tempos de atendimento programado em ambulatório, em que 2 elementos da equipa do laboratório fazem as colheitas das amostras nasofaríngeas para pesquisa de SARS-CoV-2.

A articulação dos resultados é realizada através das estruturas administrativas de proveniência e dos gestores cirúrgicos, que nas 24 horas anteriores à realização do exame invasivo ou da cirurgia contactam o cliente para

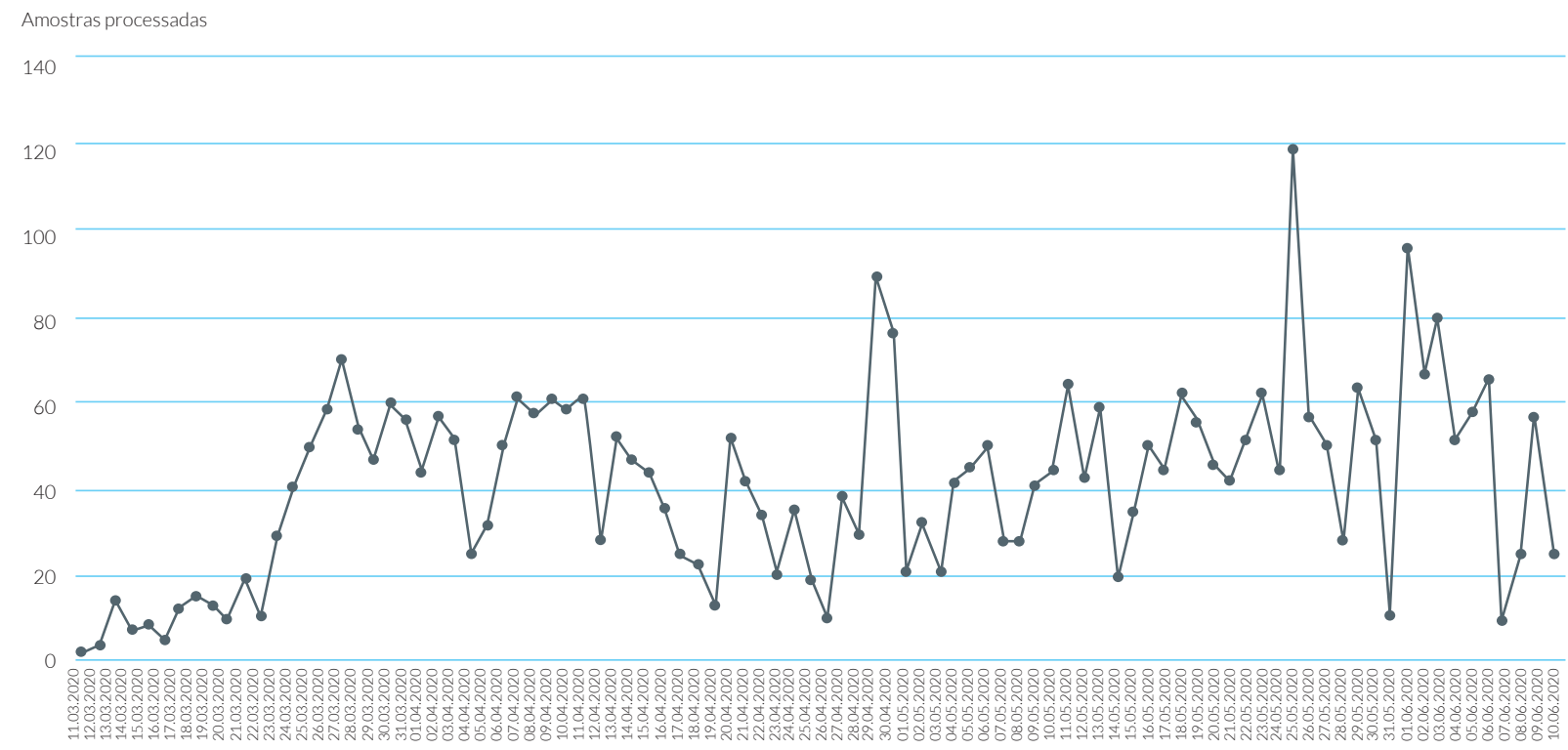

FIGURA 3. Evolução diária de amostras processadas provenientes de unidade HCIS. 


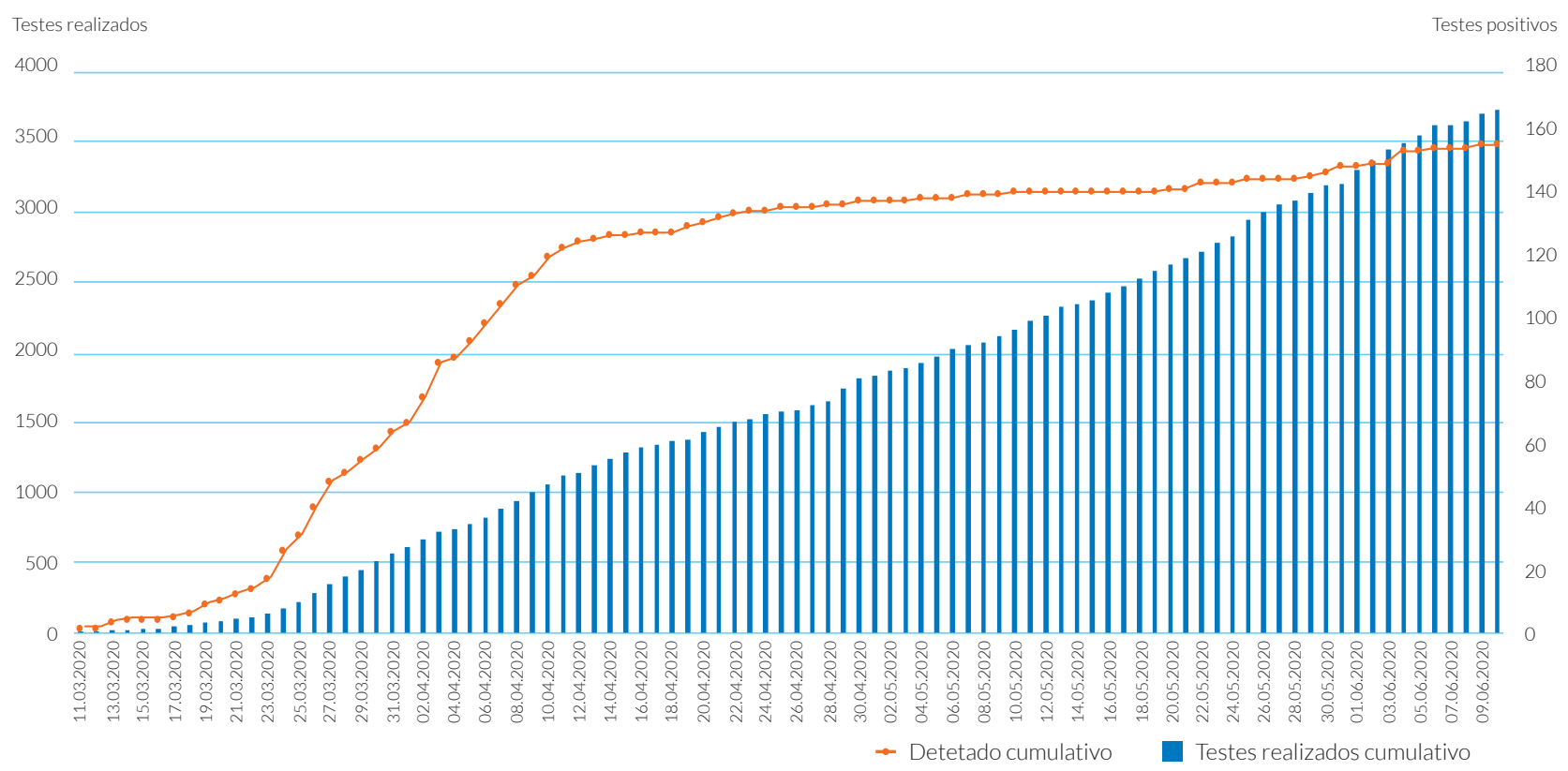

FIGURA 4. Crescimento de amostras processadas e testes positivos para SARS-CoV-2 provenientes da unidade HCIS.

saber o resultado do teste e assim procedem ao cancelamento ou à marcação do respetivo exame/cirurgia.

\section{ARTICULAČ̃̃ COM PLATAFORMA DA DGS SINAVE LABORATORIAL}

Desde a ativação da notificação laboratorial de doenças de declaração obrigatória em 2017, que o centro de Medicina Laboratorial Germano de Sousa fez parte de um projeto pioneiro com a integração automática de todos os resultados que obedeciam às regras identificadas pela DGS ${ }^{13} \mathrm{https}: / / w w w . d g s . p t / s e r v i c o s-o n-l i n e 1 / s i n a-$ ve-sistema-nacional-de-vigilancia-epidemiologica.aspx.

A interação entre as 2 plataformas informáticas, Appollo e SINAVE (Sistema Nacional de Vigilância Epidemiológica) Laboratorial permite a notificação em tempo real no momento em que o resultado fica disponível no LIS do laboratório, com uma sinalização precoce destes casos às equipas de Saúde Pública. Todas estas patologias seriam posteriormente reportadas em paralelo pelos clínicos através do SINAVE-MED.

O Centro de Medicina Laboratorial Germano de Sousa é um dos Laboratórios privados de análises clínicas que faz parte da rede de laboratórios que apoiam o Sistema Nacional de Saúde no diagnóstico de COVID-19. A necessidade de notificação diária, em tempo real, do grande número de casos testados com resultado positivo ou negativo, evidenciou o enorme contributo do CML-GS na atualização diária das estatísticas emanadas pelos boletins diários da DGS, durante a pandemia COVID-19.
Até à data da produção deste artigo e desde o dia 12 de março, foram realizados em CML-GS 137959 testes de pesquisa de SARS-CoV-2 (PCR), com uma percentagem de positividade de todas as amostras processadas de $5,95 \%$, representando cerca de $22,85 \%$ dos casos positivos nacionais.

Em HCIS foram solicitados 3719 testes, em que 2321 foram feitos em critério de Urgência/Emergência e 1398 em regime de Ambulatório, com uma percentagem de positivos de 4,19\%, representando 1,90\% dos testes positivos detetados em CMLGS.

\section{RESPONSABILIDADES ÉTICAS}

CONFLITOS DE INTERESSE: OS autores declaram não possuir conflitos de interesse.

SUPORTE FINANCEIRO: O presente trabalho não foi suportado por nenhum subsídio ou bolsa.

PROVENIÊNCIA E REVISÃO POR PARES: Não comissionado; revisão externa por pares.

\section{ETHICAL DISCLOSURES}

CONFLICTS OF INTEREST: The authors have no conflicts of interest to declare.

FINANCING SUPPORT: This work has not received any contribution, grant or scholarship.

PROVENANCE AND PEER REVIEW: Not commissioned; externally peer reviewed. 


\section{REFERÊNCIAS}

1. Direção Geral da Saúde. Orientação DGS n 015/2020 de 23/03/2020 atualizada a 24/04/2020. Lisboa: DGS; 2020.

2. Interim Guidelines for Collecting, Handling, and Testing Clinical Specimens from Persons for Coronavirus Disease 2019 (COVID-19) CDC [accessed May 22]. Available from: https:// www.cdc.gov/coronavirus/2019-ncov/lab/guidelines-clinical-specimens.html

3. Chen JH, Yip CC, Poon RW, Chan KH, Cheng VC, Hung $\mathrm{IF}$, et al. Evaluating the use of posterior oropharyngeal saliva in a point-of-care assay for the detection of SARS-CoV-2. Emerg Microbes Infect. 2020 (in press).doi: 10.1080/22221751.2020.1775133.

4. Interim Laboratory Biosafety Guidelines for Handling and Processing Specimens Associated with Coronavirus Disease 2019 (COVID-19);CDC [accessed June 2]. https://www. cdc.gov/coronavirus/2019-ncov/lab/lab-biosafety-guidelines. html

5. Marty FM, Chen K, Verrill KA. How to Obtain a Nasopharyngeal Swab Specimen. N Engl J Med. 2020; 382: e76. doi: 10.1056/NEJMvcm2010260.

6. Centro Hospitalar de Vila Nova de Gaia-Espinho [accessed May 22]. Available from: https://youtu.be/PYFSQJz7FoU

7. Guidance for laboratories shipping specimens to WHO reference laboratories that provide confirmatory testing for $\mathrm{CO}$ VID-19 virus: Interim guidance. World Health Organization 2020; WHO/2019-nCoV/laboratory_shipment/2020. Geneve:WHO; 2020

8. Guo L, Ren L, Yang S, Xiao M, Chang D, Yang F, et al. Profiling Early Humoral Response to Diagnose Novel Coronavirus Disease (COVID-19) Oxford: Oxford University Press for the Infectious Diseases Society of America; 2020

9. Guo WL, Jiang Q, Ye F, Li SQ, Hong C, Chen LY, et al. Effect of Throat Washings on Detection of 2019 Novel Coronavirus. Clin Infect Dis. 2020 (in press). HYPERLINK "https://doi. org/10.1093/cid/ciaa416" doi: 10.1093/cid/ciaa416

10. Liu W, Liu L, Kou G, et al. Evaluation of Nucleocapsid and Spike Protein-Based Enzyme-Linked Immunosorbent Assays for Detecting Antibodies against SARS-CoV-2. J Clin Microbiol. 2020;58:e00461-20. doi:10.1128/JCM.00461-20

11. To KK, Tsang OT, Leung WS, Tam AR, Wu TC, Lung DC, et al. Temporal profiles of viral load in posterior oropharyngeal saliva samples and serum antibody responses during infection by SARS-CoV-2: an observational cohort study. Lancet Infect Dis. 2020;20:565-74. doi:10.1016/S1473-3099(20)30196-1

12. Xiang F, Wang X, He X, Peng Z, Yang B, Zhang J, et al. Antibody Detection and Dynamic Characteristics in Patients with COVID-19. Clin Infect Dis. 2020 (in press). doi:10.1093/cid/ ciaa461

13. Direção Geral da Saúde. DGS-SINAVE.[acedido Jun 2020] Disponível em: https://www.dgs.pt/servicos-on-line1/sinave-sistema-nacional-de-vigilancia-epidemiologica.aspx. 